\title{
A View of Standards for Prognostics and Health Management
}

\author{
Jeff Bird and Ginger Shao \\ Standards Committee of the PHM Society \\ jbird@magma.ca \\ ginger.shao@honeywell.com
}

\begin{abstract}
The mandate of the Prognostics and Health Management (PHM) Society includes attention to standards because of their benefit in providing generally accepted technical specifications thus enabling adoption of practices across the health management domain. While there are a number of other organizations with strong foci on standards, the society recognizes the need for harmonization and coordination in this field. This communication summarizes observations from the standards panel session during 2012 PHM conference with participants from the Federal Aviation Administration, Institute for Electrical and Electronic Engineers, International Standards Organization and Society of Automotive Engineering. Steps for a way forward are proposed and mechanisms for interested parties to participate are suggested.
\end{abstract}

\section{BACKGROUND}

PHM is a diverse, multi-disciplinary domain with rapidly evolving capability needs. In this context, the PHM Society has the following objectives:

- Promote the development, growth, and recognition of prognostics and health management (PHM) as an engineering discipline;

- Support PHM education by developing standard teaching curricula in the field; and

- Establish, develop, or adopt standards, methods, and metrics in PHM.

Postings to the Society forum on standards as early as 2010, identified IEEE 1232 and Open Systems Architecture for Condition-Based Maintenance (OSACBM) as evolving standards (Uckun, 2010). In this posting the following questions were raised:

Bird et al. This is an open-access article distributed under the terms of the Creative Commons Attribution 3.0 United States License, which permits unrestricted use, distribution, and reproduction in any medium, provided the original author and source are credited.
1. Are the current standards adequate/sufficient to cover the breadth of capabilities envisioned in PHM (online diagnostics and prognostics, to name a few)?

2. Do we need new standards to focus on these critical PHM functions?

3. What should the role of the PHM Society be in proposing, developing, and maintaining PHM-related standards, legacy or new?

It should be recognized that there is diminishing return as the number of competing standards go up. Any new effort in this field, therefore, has to be measured against the expected benefit to avoid the situation depicted in Figure 1.

HOW STANDARDS PROLIFERATE:

(SEE: A/C GHARGERS, GHARACTER ENCOONGS, IN STANT MESSAGING, ETC)

\begin{tabular}{|c|c|c|}
\hline $\begin{array}{l}\text { SITUATION: } \\
\text { THERE ARE } \\
14 \text { COMPETING } \\
\text { STANDARDS. }\end{array}$ & $\begin{array}{l}14 \text { ?! RIDICULOUS! } \\
\text { WE NEED TO DEVELOP } \\
\text { ONE UNIVERSAL STANDARD } \\
\text { THAT COVERS EVERYONE'S } \\
\text { USE CASES. YEAH! } \\
\text { ( }\end{array}$ & $\begin{array}{l}\text { SOON: } \\
\text { SITUATION: } \\
\text { THERE ARE } \\
\text { I5 COMPETING } \\
\text { STANDARDS. }\end{array}$ \\
\hline & $\bigwedge 1$ & \\
\hline
\end{tabular}

Figure 1: One view of standards development (xkcd, 2013).

To address these objectives the board of the Society has approved activities in this direction through a committee on Standards on April 9, 2012. The terms of reference of this committee are to:

1. Evaluate needs and opportunities in developing and promulgating standards to achieve the objectives of the PHM Society in value added ways complementary to existing organizations like International Standards Organization (ISO), SAE, Institute of Institute of Electrical and Electronics Engineers (IEEE), International Civil Aviation Organization (ICAO), American Society of Mechanical Engineers (ASME), 
and similar organizations. Harmonization would be a particular target. A first step would be to engage with other groups by inviting them to participate in these efforts.

2. Organize and lead annual panel sessions on standards at each PHM Society conference, as appropriate;

3. Report annually to the board on issues and opportunities; and

4. Be the point of contact and coordinator for ISO Technical Advisory Group (TAG) participation.

\section{APPROACH}

This communication aims to report on the work of the committee and the most recent panel:

1. Summarize and discuss current standards groups and activities in the PHM area.

2. Identify application areas and overlaps/gaps in PHM standards across industry sectors, academia and government, examining any opportunities for harmonization.

3. Advance the processes for PHM Society outreach to the international PHM community, e.g. panels, weblinks, fora, webexes, documentation, coordinated input.

Finally, there is a proposal for a way forward for the Society to aid the broad PHM community by adding value to standards development and adoption

\section{OVERVIEW OF PHM STANDARDS}

At the 2012 PHM Conference, several existing standards developers were asked to report on the scope of their efforts. In addition, they were asked to describe why they thought standards were important and to identify any issues they saw in the development and application of standards. The complete report from the 2012 panel has been published on line (PHM Society, 2012) and includes a presentation file for each of the organizations following. The speakers from the organizations are shown in Figure 2. A summary of key points has been compiled in the following sub-sections from each of these reports. Content and status of the activities as of October 2012 and do not reflect any updates since then. Those should be sought from the individual organizations.

\subsection{ISO}

Susan Blaeser represented the International Standards Organization (ISO) and described the member roles of the United States Technical Advisory Group (TAG). Technical Committee (TC) 108 Subcommittee (SC) 5, an ANSI accredited group, is responsible for Condition Monitoring and Diagnostics, and Prognostics of Machine Systems.

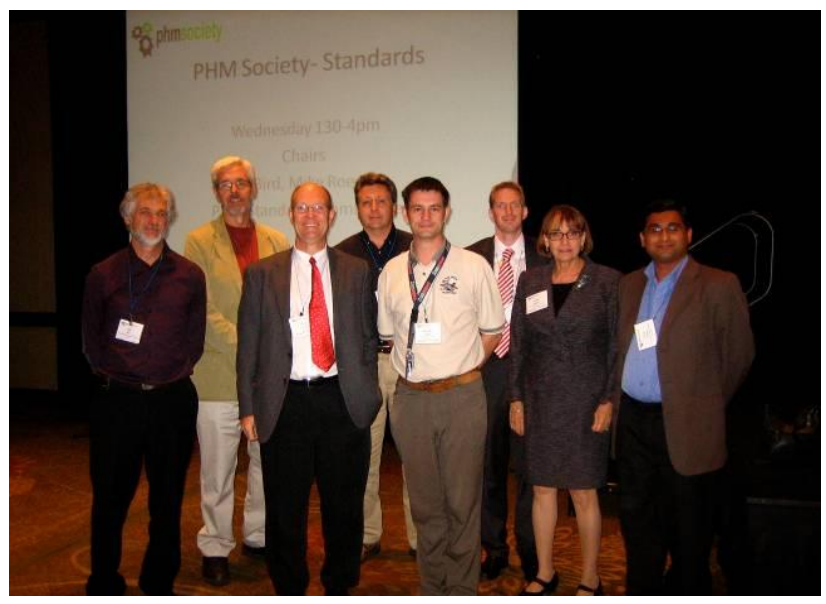

Figure 2: Standards Panelists at the 2012 Annual PHM Conference. From right to left: Jeff Bird, Tim Wilmering, Chris Pomfret, Mike Walz, Dr. Duncan Chase, David

Alexander, Susan Blaeser, and Sony Mathew.

The US TAG gathers inputs and evaluations from a wide range of organizations, for example, Association of American Railroads, BP America, Caterpillar, General Electric, John Deere, Machinery Information Management Open Standards Alliance (MIMOSA), NASA Ames, NIST, Siemens, US military organizations from the USAF, US Army, US Navy, Waukesha Magnetic Bearing and some 25 other associations, companies and universities. This is the only mechanism for U.S. stakeholders to have a voice in ISO standards development. Susan pointed out some reasons for participating in ISO through the TAG:

1. To influence the content of relevant standards.

2. To monitor future changes (advance intelligence).

3. To promote harmonization among international standards, national standards and industry standards.

4. To ensure that products can be exported worldwide.

5. To minimize the need for government regulation.

6. To establish the leadership position of your organization.

7. To network with other experts in your field.

Specific case studies and business impacts are provided at ANSI, 2013. Cost savings, health/safety, innovation, efficiency, consumer confidence, competitiveness and compatibility results are documented with clear metrics. In one example, $\$ 27 \mathrm{M}$ invested in parts standardization is projected to lead to $\$ 789 \mathrm{M}$ in cost avoidance along with other operational and schedule benefits.

The SC5 group (members from 33 countries) covers: "Standardization of the procedures, processes and equipment requirements uniquely related to the technical activity of condition monitoring and diagnostics of machine systems in which selected physical parameters 
associated with an operating machine system are periodically or continuously sensed, measured and recorded for the interim purpose of reducing, analyzing, comparing and displaying the data and information so obtained and for the ultimate purpose of using this interim result to support decisions related to the operation and maintenance of the machine system.

Diagnostic working group scope currently covers: General guidelines, Data-driven applications, Knowledgebased Performance monitoring and diagnosis. Vibration diagnostics are covered in SC 2.

The prognostics working group scope currently covers: General Guidelines, Performance based methods, Cyclic driven life usage methods and Useful life remaining prediction models under SC 5 .

Other working group activities include requirements and assessment for training and assessment bodies, condition monitoring and diagnostic techniques, data processing and applications.

\subsection{FAA}

Mike Walz of the Federal Aviation Administration provided a perspective from within the aerospace regulatory environment where standards would be applied. He noted some of the perceived promises of PHM to industry:

- Increased Safety,

- Increased usage of Life Limited Parts,

- Reduction in Unscheduled maintenance,

- Reduction in Fault Not Found, and

- Reduction in manual inspection.

His key concepts of fail-safe design, credits, end-to-end application and functional hazard assessments with safety-defined effects were discussed within a certification scenario. He provided specific details on life-limited parts including life improvement concepts.

His observations relevant to PHM systems included:

1. High bandwidth may be required for relevant data.

2. Capture and manipulation of large dimensional windows of data is typically needed on board.

3. Predictive health management

a. Does not require real time response,

b. Typically requires maturation during operational use,

c. Can be critical to support but not to flight safety,

d. An affordable approach to the maturation of flight critical health management can be to implement it first as support critical and then promote it to flight critical status with the required flight critical hardware.

\subsection{SAE General}

David Alexander presented an overview of the standards work of the SAE International. An SAE IVHM Steering Group was formed in June of 2010 with the objectives to:

1. Coordinate/Integrate Health Management Standardization in the SAE Technical Standards Programs.

2. Map and monitor IVHM relevant standards, practices and activities.

3. Identify future needs.

4. Promote PHM and IVHM systems to key stakeholders.

5. Advance IVHM technologies through standards and other fora.

This steering group aims to provide integration of IVHM activities across a wide range of SAE committees including: HM-1 IVHM, E-32- Aerospace Propulsion System Health Management, G-11- Reliability, Maintainability, Supportability and probabilistic Methods Systems, G-11SHM - Structural Health Monitoring and Management, A-5- Landing Gear, AS-3- Fibre Optics, S18- Safety Assessment G-18- RFID Aerospace Applications, A-6- Actuation, Control and Fluid Power Systems, E-36- Electronic Engine Controls and AE-5 Aerospace Fuel, Inerting and Lubrication Systems. A full organization chart of the aerospace committees is provided at SAE, 2013.

These committees develop and distribute information in the following forms: aerospace resource document, aerospace information reports, aerospace recommended practices, aerospace materials specifications and aerospace standards.

\subsection{SAE HM-1}

Chris Pomfret on behalf of the chair Mike Roemer summarized the work of the SAE HM-1 group. The committee goals are to:

1. Review industry experience and the "state-of-the-art" technologies for integrated vehicle health management.

2. Publish documents known as SAE Aerospace Standards (AS), Aerospace Recommended Practices (ARP), Aerospace Information Reports (AIR), and Aerospace Resource Documents (ARD).

3. Analyze and report on various approaches to IVHM (e.g. health management systems, fault prediction capabilities, data standards, ground software interfaces, etc.).

4. Develop standards and recommended practices for IVHM equipment and techniques, e.g. overall system architecture, determination of system health, 
identification of signals common to IVHM systems, etc.

5. Develop new requirements and uses for IVHM technologies to promote cost effective operation of vehicles.

The aim is to develop a cornerstone aerospace Recommended Practice document with representatives from OEMs, Tiers 1-3, Technology, Government/Regulatory, Operator, Maintenance Repair and Overhaul (MRO), Research and Consultant communities. In addition, advisory documents for business, technologies and applications are currently being developed by several task groups:

1. Design

2. Architecture

3. Verification and Validation, Metrics and Certification

4. Data and Information Management

5. Business case

6. Avionics

A number of documents on priority subjects are in the first draft stage.

\subsection{SAE E-32}

Dr. Duncan Chase, chair of E-32 provided a summary of the work of the Aerospace Propulsion Systems Health Management committee operating under SAE. The scope of the broad-based, international committee work encompasses:

1. All aspects of fixed and rotary wing propulsion that relate to the efficiency and degradation of the systems, including life usage and helicopter drive train mechanisms, and

2. Technical elements include condition monitoring, diagnostics, and, more recently, prognostics, which predict failures and the anticipated necessary maintenance actions, based on state awareness and anticipated system usage.

$\mathrm{He}$ identified the challenges in reviewing and updating existing documents on a five-year basis, while still developing ones related to new and evolving technology. E-32 is working to classify their work into sense, acquire, transfer, analyze, act and general categories.

\subsection{IEEE PHM}

Sony Mathew presented the status of the broad-based, international Prognostics and Health Management of Electronic Systems working group being conducted under the auspices of the Reliability Society of the Institute for Electrical and Electronic Engineers.
He identified a number of challenges for PHM of electronics:

1. PHM is not part of the conceptual design of the system.

2. Intermittent Failures/ No Fault Found are prevalent.

3. Inadequate physics-based models exist for electronics.

4. Identification and selection of precursor parameters to monitor is difficult.

5. Availability and selection criteria for sensors need to be addressed

6. The choice of algorithms for prediction must be investigated to provide information on which algorithm is the best. Similarly, uncertainties in the initial modeling of the system need to be considered

7. Aging of systems (i.e., the shift in normal behavior over a period of time/ usage) needs to be accounted for

8. Integration of canary devices on host systems

9. Data fusion and fault isolation at the system-ofsystems level

10. Software-hardware interactions. How should one account for hardware failures caused by software glitches and vice-versa?

11. Implementation at enterprise level

12. Changing the maintenance culture

13. Education: lack of trained professionals in PHM

14. Business Case: quantifying the cost of implementation of PHM vs. maintenance savings

15. Regulatory issues.

16. Lack of standards for PHM

The goal is to come up with a standard, P1856 "Standard Framework for Prognostics and Health Management of Electronic Systems". The purpose of this standard will be to:

1. Classify and define the concepts involved in prognostics and health management of electronic systems; and

2. Provide a standard framework that assists practitioners in the development of business cases, and the selection of approaches, methodologies, algorithms, condition monitoring equipment, and strategies for implementing prognostics for electronic systems.

The scope of the work is to cover: all aspects of prognostics and health management of electronic systems, including definitions, approaches, algorithms, sensors and sensor selection, data collection, storage and analysis, anomaly detection, diagnosis, metrics, life cycle cost of implementation, return on investment and documentation. 
This standard is to describe a normative framework for classifying PHM capability and for planning the development of PHM for a system or product. This standard is to provide information to aid practitioners in the selection of PHM strategies and approaches to meet their needs.

\subsection{IEEE SCC-20}

Tim Wilmering gave a summary of the work of this Standards Coordinating Committee which operates under the Institute for Electrical and Electronic Engineers. SCC-20 seeks to provide guidance for the management, development, and maintenance of language and interface standards supporting system-level (onboard and off board) automatic test and diagnosis. These standards include (but are not limited to) test requirements, test programs, test procedures, diagnostic knowledge, maintenance information, and major hardware subsystem interfaces between and within Automatic Test Systems (ATS).

The SCC-20 organization includes subcommittees on Hardware Interfaces, Diagnostics and Maintenance Control (Information Exchange for Reasoning Systems development, Operation and Maturation), Test and Automatic Test System Description and Test Information Integration (Automatic Test Markup Language activities). Within each subcommittee, working groups are assigned to develop specific IEEE standards documents.

For example the Diagnostics and Maintenance Control (DMC) subcommittee, developed IEEE 1232-2010 standard "Artificial Intelligence Exchange and Tie to All Test Environments" (AI-ESTATE). It has the purpose to provide formal models of diagnostic information to ensure unambiguous access to and understanding of the information supporting system test and diagnosis. The standard defines formal information models and software services specific to several different types of diagnostic reasoners. The purpose is further to provide semantically sound definitions of diagnostic knowledge and to specify software exchange and service interfaces that are consistent with the state of the practice in modern test and diagnostic systems (e.g., the use of XML and web services).

A specific example of a software standard is IEEE 16362009 "Software Interface for Maintenance Information Collection and Analysis" (SIMICA). The purpose of this standard is to specify a software interface for access, exchange, and analysis of product diagnostic and maintenance information. This document addresses the pervasive need of organizations to assess the effectiveness of diagnostics for complex systems throughout the product life cycle. The use of formal information models enables exchanging historical maintenance information between information systems and analysis tools. The models facilitate creating open system software architectures for maturing system diagnostics.

\section{DISCUSSIONS AND ISSUES}

The PHM Society has diverse goals of technology development and application in service.

In the PHM technology development domain the standards issues and opportunities seem to be:

1. Understanding the real needs of the OEMs and the end users including access to operations data,

2. Exploiting applications across sectors or platforms,

3. Understanding any regulatory constraints,

4. Maintaining awareness of best practices in architecture, techniques, processes and business cases from various sectors and platforms, and

5. Accessing accepted, technology maturation processes and demonstrators.

In the PHM technology application domain the standards issues and opportunities seem to be:

1. Understanding the evolution of regulatory and technology constraints on product capability and use along a supply chain,

2. Having commonly accessible methods, platforms and facilities to evaluate the capabilities of technologies and equipment offered to them, and

3. Adapting technology offerings to the right product or process, i.e., on board, off-board, certified, noncertified, support-critical, flight/operations-critical.

The three domains could be seen to have common issues related to standards and therefore present opportunities in:

1. Protecting intellectual property for commercial advantage,

2. Providing appropriate information for the whole supply chain over a product life cycle,

3. Contributing time and support costs for employees to participate in developing standards in a timely manner,

4. Ensure that government regulations do not limit their commercial development,

5. Understanding any inherent uncertainties in risk sharing, warranty and contractual environments,

6. Developing standard terms and nomenclature, and

7. Providing PHM educational material for developing employees, both at entry level and throughout their careers

The PHM Society is examining these issues and opportunities through panels at its conferences and the ongoing activities of its Standards Committee. The issues 
above will be circulated and discussed at the 2013 Annual Conference.

A related PHM Society activity, which addresses the nomenclature and education issues, is the Education and Professional Development Committee. The current project is to develop a taxonomy of skills and capability levels for the PHM community. Its work will complement related activities in many of the previously presented groups.

One particular initiative that addresses the accessibility and benchmarking issues is the PHM Society's participation in ISO.

With broad international and sectoral representation, the ISO involvement of the PHM Society gives this community input to and evaluation opportunities to new standards. It is worth a mention that since participation in the TAG requires an annual membership fee, this is a particular benefit to small businesses, consultants, and faculty. Draft versions of standards in development are thus available to the community through the Society, which then distributes and coordinates responses to the TAG according to fixed development schedules. The Society must commit to paying annual dues and managing this process, which can engage both technology and application domains of the PHM community not already served by the US TAG.

\section{COORDINATION APPROACH FOR PHM STANDARDS}

Currently working documents across the full spectrum of the ISO TC 108 SC5 (Condition Monitoring and Diagnostics of Machine Systems) are offered through the ANSI coordinator to the PHM Society TAG members, currently, Andrew Hess and Jeff Bird. The following process is proposed to promulgate widely in the Society such documents and gather reviews and opinions for consideration by the US TAG and so the ISO:

1. Establish a web-based, working group of standards participants (StdsWG) in the PHM society,

2. PHM TAG member assesses the likely interest in a document being assessed by the US TAG and assigns a review manager within the StdsWG,

3. Document is requested by the PHM TAG member from the US TAG,

4. Document and templates for comments are made available to the StdsWG, under ISO dissemination rules, along with the date for return of the comments,

5. Comments are compiled by the assigned review manager in the StdsWG and submitted to the PHM TAG member(s) with recommendations and comments, as appropriate, and

6. PHM TAG member submits a final position to the US TAG.
This approach attempts to manage this process across a wide community for different subsets of stakeholders depending on the specific document scope and objectives. It proposes to use a management and dissemination process like those of the Society's journal and conference technical programs. So then this process could be applied to any standards contributions within the PHM Society to other organizations developing and harmonizing standards.

\section{CONCLUSIONS AND WAY FORWARD}

The complex, multi-disciplinary PHM community is expected to benefit from participation in the development and use of standards. However, the processes and scope of a number of evolving standards under a number of established technical organizations may be seen as overlapping and complicated from the point of view of PHM organizations.

The PHM Society Standards Committee proposes coordinating actions to establish a web-based PHM Society Standards Working Group accessible to those in the Society to participate in, and benefit from standards development and promulgation, for example, the ISO PHM standards process through the US TAG.

The committee will continue to:

1. Evaluate needs and opportunities in developing and promulgating standards to meet the objectives of the PHM Society in value added ways complementary to existing organizations. Harmonization would be a particular target including inviting other groups to participate in the PHM Society.

2. Organize and lead annual panel sessions on standards at each PHM Society conference, and other conferences as appropriate.

The committee will also ensure cross-pollination of activities with the Education and Professional Development Committee, e.g. development and use of the PHM taxonomy.

In the longer term, the PHM Society seeks to work with appropriate organizations to develop needed materials and opportunities. In this direction, the PHM Society is establishing a comprehensive set of technical cosponsorships with major organizations. Currently, these include Condition Monitoring and Diagnostic Engineering Management (COMADEM), Cranfield IVHM Centre, Society for Machinery Failure Prevention technology (MFPT) and SAE.

Interested parties are invited and encouraged to contribute by contacting one of the authors or participating in the online forum at www.phmsociety.org/forum/592. 


\section{ACKNOWLEDGEMENTS}

The Standards Committee members are: Jeff Bird, Kai Goebel, Mike Roemer, Ginger Shao, and Tim Wilmering. Advisory contributions are acknowledged from members of the 2012 Panel: Susan Blaeser, David Alexander, Chris Pomfret, Duncan Chase, Mike Walz, and Sony Mathew.

\section{REFERENCES}

ANSI (2013). Standards Boost Business website http://www.standardsboostbusiness.org/, Accessed August 2013.

PHM Society (2012). Standards Panel http://www.phmsociety.org/events/conference/phm/1 2/phm_standards, Accessed August 2013.

SAE (2013). SAE Aerospace Council Organization Chart, http://www.sae.org/standardsdev/aerospace/2013_Ae roOrgChart.pdf, Accessed August 2013.

Uckun (2010). PHM Society Standards Forum Post. http://www.phmsociety.org/node/397

xkcd (2013). Online cartoon http://xkcd.com/927/ Accessed August 2013.

\section{BIOGRAPHIES}

Jeff Bird is currently a consultant with TECnos Consulting Services, Ottawa, Canada. His present avocations include advancing the art, science and business of prognostics and health management in diverse fields. Specifically, he leads PHM Society board initiatives in Education and Professional Development as well as Standards. He has the honour of serving as Vice President of the society now in a second term. $\mathrm{He}$ recently completed one career spanning 30 years as a Research Officer at the Gas Turbine Laboratory of the National Research Council Canada. His published research there included gas turbine dynamics and performance, health monitoring and management, adverse environments, and uncertainty. Previously he worked as an Operational Research officer in the Department of National Defence where he enjoyed contributing to airlift and search and rescue planning. He studied at the University of Toronto (Engineering Science- Aerospace) and at Carleton University (Mechanical, Aerospace and Systems)

Dr. Ginger Shao is currently the Staff Systems Engineer at Honeywell Aerospace, leading CBM systems design and development for propulsion engines and rotor aircraft health management. Her specific interests include algorithm development for diagnostics and prognostics, systems modeling, systems architecture design and testing, and the CBM system integration with logistics, with published papers and patents. She is currently serving as a member of the SAE HM-1 Standard Committee for IVHM system architecture and requirements standard development. She has chaired PHM conference sessions on PHM tutoring, panel discussions, and luminaries, and is an active member of the PHM Society Standard Committee. She graduated from Peking University in China, has a Ph.D. of Atmospheric Sciences from the Colorado State University, an MBA from the University of Arizona, and is 6-sigma Blackbelt certified. 